\title{
Detection of explosives dogs v/s sensors
}

\author{
Ayshwarya Girish \\ Student, Forensic Science Amity Institute of Forensic Science, Noida, Uttar Pradesh, India \\ *Corresponding Author: \\ Email: ayshwerya16@gmail.com
}

\begin{abstract}
The paper present some characteristics of a dog's sensing power towards explosives and a challenging threat on dog squad by the introduction of machine based sensors. It includes the working of a potential squad and its drawbacks in certain fields.

In this technological era scientists are busy with technology and machines for all purposes including explosive detecting machines. Some recent studies shows sensors are mimics of nose of a dog with improvements and are capable of detecting explosives very effectively but are they quite alike dog's olfaction without drawback is the common question arising.
\end{abstract}

Keywords: Explosives, Olfactory, Psedogenes, Nasal epithelium, Corroborative, Vomeronasal, Investigation, Detectors.

\section{Introduction}

The term dog squad means a group of officials including trained dogs and handlers assisting a crime scene investigation or sometimes in detecting illegal matter. In other words, we can say that they are the leads to the suspect. The hard work put by handlers, trainers and dogs results in the formation of an effective squad. There are many factors which influence in the formation of a potential dog squad which may also include breed of dog, handler's qualities, infrastructure of training, understanding between dog and handler etc. Only an effective team could bring out the evidence which lead to the crime or else it may result in deviation followed by misleading and suspicion on innocent.

Dog squads assist in police, military, and fire and rescue. They help police officers in tracking and trailing evidences in investigation. In military they are used in detection of explosives, trailing etc. In fire and rescue dogs help in finding victims after natural disaster (earth quake, storm, avalanche etc.) and manmade disasters (building collapse, explosions etc.). They are chosen for their peculiarity in sniffing, ability to understand, and for their behavioral psychology. Their intelligence, behavior, psychology and biological functioning are the factors which adapt them to this field. Their role is changing considerably; they are used in different branches that are from crime scene investigation to cadaver dogs.

Nowadays they are facing competition from technical side, introduction of detecting machines and sniffers have a great chance in obsoleting the dog from this field at the same time certain draw backs are shown from the technical side too and also dog trail evidences are not given much weightage as other evidences in India. $^{1}$

Dogs: Elephant is considered as the $3^{\text {rd }}$ most intelligent animal followed by pig and dog. An elephant could sense the scent of water even from miles away it is scientifically proven that pig and elephant have more olfactory cells than dogs, in short an elephant or a pig have high capability to identify scent than a dog but due to some reason they are discarded from official duties. But nowadays in Israel pigs are used for finding victims who are trapped under earth after disasters like earthquake and also used in explosive detection (Israel have their own pig squad for this purpose). ${ }^{6}$ No matter how powerful in smelling they are, when it comes to the behavioral psychology they cannot be trained for the purpose that a dog does today. Their size, maintenance, behavior and ability to get trained all matters.

The nasal epithelium of dog contains olfactory receptors which are bonded with odorant molecules, this send signals to olfactory bulb and various areas of cortex of the brain where further interpretations are followed. The olfactory cells as well as vomeronasal organ (also called Jacobson's organ) behind the canine teeth helps in smelling. A dog contains around 220 million olfactory receptor genes, ${ }^{7}$ which means they have 40 times more smelling power than a human being. A research group found that among the genes $20 \%$ of the genes are pseudogenes that they do not produce proteins. More number of pseudogenes results in poor sensing power. This percentage of pseudogenes varies from breeds to breeds. Boxers have less acute sense of smell due to the presence of more number of pseudogenes. When they breathe air flows through the nostrils along the epithelial lining containing olfactory receptors these receptors capture the molecules and interpreted.it is found that olfactory regions are present in the expiration tracks too confirming a dog can sense air when it inhales as well as exhales.

Dogs have been shown to be capable of learning when only 9 days old. Some trained target scents to future narcotics defecting canines that are only 10 days old. The climate, temperature, pressure, wind, disease, and sometimes surroundings challenges the accuracy of detection.

Scope of Dog Squad: Voices arise against the use of dog squad. According to the court an-evidence recovered by dog squad cannot stand alone to prove 
question of facts instead it can only be used as a corroborative evidence. This is the only drawback of dog squad in crime scene investigation. But in explosive, narcotics, weapon detection and further more dogs shows immense potential in these fields.

It is an era of terrorism, narcotics alcoholism, explosive detectors and other machines alone could not always run over them. There are some drawbacks such as handling capacity, electric and magnetic fluctuations, high maintenance, life span, machinery failure etc. and also they are quite slow in detection when compared to a trained dog.

Researchers were talking about the possibility that trained dogs will be obsoleted from this field with the emergence of more accurate machines but according to the new studies till now no machine is proved to be more accurate and significant than a trained dog.

The Exceptional Breeds: People often wonder why only specific breeds are used in police and military purpose. The answer revolves around the biological, behavioral and physical pattern of the breed. One factor in selecting breeds depend upon the olfactory cells present in the nasal epithelium. Boxers have less number of olfactory cells which means they are very poor in locating, whereas blood hound, mallinois, Labrador, Doberman and German shepherd have got exceptionally more number of cells and they are active in trailing.

The other factor is physique of the dog, small sized dog such as beagle to large sized German shepherd is used but depending on the field for example beagle is used in finding victims under collapsed building, their physique the small sized body will allow them to move around without restrictions. The other important factor is degree of ferociousness in dogs for example dash is a German breed which is short furred and have good smelling capability but it is a very ferocious dog there are chances that the dog may attack the suspect or others, such dogs are excluded from this category instead dash could be used in other activities such as fetching and hunting.

Sometimes dogs are used according to the climate of the country. Bloodhound, German shepherd, Labrador are the main dogs used in foreign countries this is due to the fact that they can adapt to the climate and won't get interfered during working.

According to the trainers one of the major drawbacks in Indian dog squad is that they use foreign breeds such as German shepherd, Doberman etc. which finds it hard to thrive certain seasons. When summer approaches German shepherd get boiled throughout the climate where as Doberman shivers during winter, this may affect their ability to sense scent and challenges their job. Proper precautions must be done while handling them during such seasons. Selection of dogs must be done by putting all these factors into consideration, In order to raise a potential squad.
Drawbacks in Dog Squad: Dogs can't talk and the evidence recovered is considered as hearsay evidence. ${ }^{17}$ Some suggested that perplexity of scent, disturbances from the surrounding and handler's loss of interest may deviate the dog from suspect to decoy. Disturbances can be smoke, climate, traffic, rain, other scent, disease etc.

When it comes to crime scene investigation be it tracking, trailing or scent line up any findings recovered by the dog corroborative evidence. There are chances for spoliation of other potential evidences when a dog squad search begins. Tiny droplet of blood and body fluids, soil, hair etc. which are unnoticed by experts while collecting have a high degree chances for spoliation.

Climate influence a lot in dogs while absorbing smell into olfactory epithelium. Too much pressure will discard the scent from air that is inhaled; this may either lead the dog to decoy or perplexity.

Certain diseases like nasal tumor, canine distemper, seizure disorder, chronic renal failure, diabetes mellitus creates decoy in an investigation. A dog and handler are both important factor in dog squad. An effective team leads to a successful conclusion. The voice of handler, his gesture and interest effect the dog, any negligence leads to decoy. A handler's voice must me strict, straight, and sound. Shaking of shoulders, waving of hands creates disturbances and irritation in dogs. The handlers are often advice to maintain strict gesture. Choosing old and tired dogs for investigation often finds difficult and ineffective. Rules must be put forth in choosing such dogs.

Through perseverance, hard work and training of both dogs and handlers and also improving the infrastructure can bring out an effective team.

A Future Threat: Terrorist attacks have increased since last few years and their activities are showing up every now and then in different parts of the world. The basic weapon they are using is religion. They often forget to remember that human kind are from the same origin. This oblivion creates disasters and tragedies all around us. Their moto is killing, they do not focus on just a single political figure or a business tycoon instead they aim for mass killing and destruction. And the perfect weapon is explosives. This era is the emergence of IEDs (improved explosive devices) for example letter bomb, booby traps, car bomb, suicide bombs etc.

Explosives are the greater threat to human kind. It can bring destruction on humans, animals and other useful resources. There are detecting machines and sniffers, officers and dogs all over the airport, metro, borders, and in public checking but still terrorist manages to sneak them into cast jinx on the population.

Failure to identify the explosives results in successful terrorist attacks. Once we find a way to tackle this problem many families won't shatter, children don't get orphaned and resources will be undisturbed 
Table 1: Technology based device v/s trained do. ${ }^{10}$

\begin{tabular}{|l|c|c|}
\hline \multicolumn{1}{|c|}{ Aspects } & Device & Dog \\
\hline Initial cost & $\$ 45,000$ & $\$ 6,000$ \\
\hline Target chemicals & Parent explosives & Odorant signature \\
\hline Performed by & Handler(always) & Off lead or with handler \\
\hline Electric /magnetic field influence & Interpret the work & Do not interpret the work \\
\hline Speed & Slow & Very fast \\
\hline Sensitivity & Problematic & Very good \\
\hline Mobility & Limited & Very sensitive \\
\hline Scent to source & $\begin{array}{c}\text { Difficult with present } \\
\text { technology }\end{array}$ & Natural and quick \\
\hline Life span & 10 years & 6 to 8 years \\
\hline Operators/handlers influence & Less a factor & Potential factor \\
\hline
\end{tabular}

According to this report in some aspects explosive detecting machines shows more significance than dogs but at the same time dog has got its own uniqueness and importance in other aspects.

But when it comes to safety and protection of population dogs are more desirable due to their peculiarity in quickness, sensitivity, nature, mobility and independent working. No technology is found to be more-quick than a dog in detecting desired illegal materials.

According to the experts there are more than 3,600 types of explosives existing today. Majority of them have a parent explosive and these bases are used in training dogs, the same procedure is used in technology based devices and sniffers. The problem is that the dogs and machines fail to identify an explosive which belong to the minority category, the one with unique bases. In such case they can't detect its presence and fail to dismantle the explosive. Improving this part will bring a big support to counter terrorism.

\section{Conclusion}

There has been a great increase in the development of trace and ultra- trace explosive detection in last decades mainly because of the globalization of terrorist acts. Apart from dogs scientists are busy in inventing mechanical sensors inspired from dog's olfactory perception but it is a property which is hard to replicate properly and projecting their drawbacks such as cost, defect and other source interpretations questions the safety of public. It is the highest time to make progress towards the development of artificial intelligence which is portable and replicate a dog nose perfectly in mechanism devoid of drawbacks. Interpretation and detection of low volatile explosives is still challenging.

\section{References}

1. Supreme court criminal digest (1950 -2010) pg. 2817.

2. Adaption and natural selection; Dog illustrations by Chet Jezierski, Š American Kennel Club; pg: 1-2.

3. Slabbert, J. M.; O. A. E. Rasa (1997). "Observational learning of an acquired maternal behaviour pattern by working dog pup: an alternative training ethod?" Applied Animal Behaviour Science. 53(4):309-316.
4. Burch, Mary R; Duane Pickel (1990). "A toast to Most: Konrad Most, a 1910 pioneer in animal training" (Full text). Journal of Applied Behavior Analysis. 23(2):2634. doi:10.1901/jaba.1990.23263. PMC 1286234. PMID 16795731.

5. Burch, Mary R.; and Jon S. Bailey (1999). How Dogs Learn, New York: Howell Book House ISBN 0-87605$371-1$.

6. Police and military dogs, John J Ensminger, pg22.

7. Article Stanley Coren PhD., DSc, FRSC, Canine Corner.

8. http://www.livelaw.in/govt-proposes-new-rules-regulatedog-breeders/.

9. Article; explosive detection dogs introduced to British airport to screen cargo. Published 7 May 2018; From:Department for Transport, Civil Aviation Authority, and Baroness Sugg CBE.

10. Police and military dogs, John J Ensminger pg, 231. 